\title{
Dietary guidelines and patterns of intake in Denmark
}

\author{
Jóhanna Haraldsdóttir \\ Research Department of Human Nutrition, Royal Veterinary and Agricultural University, Rolighedsvej 30, \\ DK-1958 Frederiksberg, Copenhagen, Denmark
}

\begin{abstract}
Food-based dietary guidelines in Denmark have usually been expressed in simple terms only and need to be elaborated. Quantitative recommendations on fruit and vegetable intake were issued in 1998 , recommending $600 \mathrm{~g} / \mathrm{d}$ (potatoes not included). This paper is based on a national dietary survey in $1995(\mathrm{n}=3098$, age range $1-80$ years $)$ supplemented with data from a simple frequency survey in $1995(\mathrm{n}=1007$, age range $15-80$ years) and from the first national survey in 1985 $(\mathrm{n}=2242$, age range $15-80$ years). Only data on adults are included in this paper. Fat intake, saturated fat in particular, is too high (median intake $37 \%$ energy and $16 \%$ energy, respectively). Main fat sources are separated fats (butter, margarine, oil, etc.: $40 \%$ ), meat (18\%), and dairy products $(21 \%)$. Total fat intake decreased from 1985 to 1995 but fatty acid composition did not improve. Dietary fibre intake is from 18 to $22 \mathrm{~g} / \mathrm{d}$ (women and men, respectively) with $62 \%$ from cereals, $24 \%$ from vegetables and $12 \%$ from fruit. Mean intake of vegetables and potatoes was from 200 to $250 \mathrm{~g} / \mathrm{d}$ (women and men, respectively). Mean intake of fruit and vegetables (potatoes not included) was $277 \mathrm{~g} / \mathrm{d}$, or less than half of the new recommendation $(600 \mathrm{~g} / \mathrm{d})$ ). Only $15 \%$ of participants in the frequency survey reported consuming both fruit and vegetables every day, and only $28 \%$ reported to do so almost every day. In conclusion, dietary intake in Denmark is characterized by a high intake of saturated fat and total fat, and by a relatively low intake of fruit and vegetables.
\end{abstract}

Food-based dietary guidelines: Denmark

In Denmark there are basically two sets of official dietary guidelines: nutrient recommendations and food-based guidelines. Whereas the main aim of the nutrient recommendations is to serve as a set of tools for professionals working within the areas of food, nutrition and health, the Danish food-based guidelines mainly aim at communicating a simple message to the general public.

The nutrient recommendations were developed in cooperation with the other Nordic countries, by an expert group, and have their official Danish status through the Ministry of Food. The most recent edition is from 1996 (Nordic Council of Ministers, 1996). These recommendations include the macronutrient composition of the diet, micronutrient intake and reference values for energy intake (see Tables 1 and 2). The 1996 publication includes separate chapters for all nutrients, presenting the scientific data and the judgements on which the recommendation is based. It also includes a section on the principles behind the recommendations, and their use for planning and evaluating dietary intake.

The Danish food-based dietary guidelines are expressed in terms of seven simple sentences, 'De syv kostraad' (Table 3). The most recent version was issued in 1995 by the national Consumer Agency, in cooperation with the national Veterinary and Food Administration, and the Danish Nutrition Council (National Consumer Agency, 1995). These guidelines do not include any recommendations on absolute quantities of intake, but use vague terms like 'plenty of' or 'small amount of'. The Consumer Agency has illustrated the meaning of these recommendations by the 'Food circle', where minimum amounts for foods like fruit, vegetables and cereals are indicated. These minimum amounts have, however, never obtained the status of generally accepted, official recommendations. An official quantitative recommendation on fruit and vegetable intake was issued in the autumn of 1998 by the Ministry of Food (Trolle et al. 1998), recommending $600 \mathrm{~g}$ of fruit and vegetables per day (potatoes not included). This is much more than the previously suggested minimum value from the Consumer Agency ( $250 \mathrm{~g}$ vegetables and $100 \mathrm{~g}$ fruit). A quantitative recommendation on fish intake has also been issued by the Ministry of Food; $200-300 \mathrm{~g} /$ week. This value is based on an evaluation balancing the positive nutritional aspects against the potential toxicological aspects.

A direct link between the Danish nutrient recommendations and food-based dietary guidelines does not exist, 
Table 1. Nordic nutrient recommendations, content of the 1996 publication*

1. Recommendations for planning dietary intakes

Macronutrient composition (E\%)

total fat, fatty acids

total carbohydrate, dietary fibre (added sugar) protein

Intake of vitamins and minerals

Planning diets for heterogenous groups content of vitamins and minerals per MJ

Reference values for energy intake, group level

Recommendations on intake of salt

Recommendations on intake of alcohol

2. Reference values for evaluating nutrient intake

Lower limits for intake of vitamins and minerals

Upper limits for intake of vitamins and minerals

3. Background and principles for nutrient recommendations

4. Practical use of the recommendations

Planning of diets

Education and information

Food and nutrition policy

Evaluation of nutrient intake

5. Chapters on energy and nutrients (32 chapters)

6. Other issues

Antioxidants and other biologically active substances

Breast-feeding

Meal pattern

Beverages

Intake of vitamins and minerals in the Nordic countries

History of nutrient recommendations in the Nordic countries

*Nordic Council of Ministers, 1996.

although the general public often expects that food guidelines are meant to ensure that recommended intakes are met for all macro- and micronutrients. Such a link would demand specification of food quantities in the food-based guidelines.

The data on food and nutrient intake presented in this paper are mainly derived from a national dietary survey in 1995, supplemented with results from a simple food frequency survey in 1995 and a previous national survey in 1985.
Table 3. Danish food-based dietary guidelines

'De syv kostraad' (National Consumer Agency, 1995)

- Eat plenty of bread and cereals

- Eat fruit and plenty of vegetables every day

- Eat potatoes, rice or pasta every day

- Eat fish and fish products often

- Select low-fat milk and milk products

- Select low-fat meat and meat products

- Use only small amounts of butter, margarine and oil - and use sugar and salt with moderation

Recommendations for fruit and vegetable intake (Danish Veterinary and Food Administration: Trolle et al. 1998)

- $600 \mathrm{~g}$ fruit and vegetables per day*

${ }^{*}$ Potatoes not included.

\section{Methods}

National dietary survey 1995 from the Danish Veterinary and Food Administration (Andersen et al. 1996)

Subjects: A total of 3098 persons (1516 men, 1582 women), $1-80 \mathrm{yrs}$, participated in the survey. Within the adult group, 15-80 yrs, the sample size was 1837 (904 men, 933 women). Participation rate was $58 \%$ for adults and $82 \%$ for children (1-14 yrs). The sample was drawn from the central population register and stratified by sex and age. Within each stratum a random sample was drawn, based on date of birth. Population means were calculated as weighted means.

Dietary intake data: Data were collected through a $7 \mathrm{~d}$ food record with estimated quantities. Quantities were estimated using household measures, photos and standard weights. Data collection was spread over three seasons - January/ February, April/May, August/September 1995 - with approximately one-third of the sample in each season. Intake of foods and nutrients was reported as $\mathrm{g} / \mathrm{d}$ and as $\mathrm{g} / 10 \mathrm{MJ}$.

\section{Frequency telephone survey 1995 from the Danish} Nutrition Council (Haraldsdóttir et al. 1996)

Subjects: 1007 persons (461 men, 546 women), 15-80+ yrs, participated in the survey. Participation rate was $62 \%$. The

Table 2. Comparison of energy and nutrient intakes in Danish adults, 15-80 years, with recommended intakes. Median intakes (10th and 90th centiles) from a national dietary survey in 1995 (Andersen et al. 1996)

\begin{tabular}{lccc}
\hline & $\begin{array}{c}\text { Men } \\
(n=904)\end{array}$ & $\begin{array}{c}\text { Women } \\
(n=933)\end{array}$ & $\begin{array}{c}\text { Recommended* } \\
\text { intake }\end{array}$ \\
\hline Energy MJ/d & $11 \cdot 5(8 \cdot 0-15 \cdot 6)$ & $8 \cdot 7(6 \cdot 0-11 \cdot 7)$ & - \\
Fat (\%energy) & $37(31-44)$ & $37(30-43)$ & 30 \\
$\quad$ Saturated fatty acids (\%energy) & $16(12-19)$ & $15(12-19)$ & max. 10 \\
Monounsaturated fatty acids (\%energy) & $11(9-14)$ & $11(9-13)$ & $10-15$ \\
$\quad$ Polyunsaturated fatty acids (\%energy) & $4 \cdot 9(3 \cdot 6-6 \cdot 7)$ & $4 \cdot 8(3 \cdot 6-6 \cdot 5)$ & $5-10$ \\
Carbohydrate (\%energy) & $42(35-51)$ & $45(38-52)$ & \\
$\quad$ Dietary fibre, & $22(14-33)$ & $18(11-26)$ & $25-35$ \\
$\quad$ g/d & $19(14-26)$ & $21(15-28)$ & $-\dagger$ \\
$\quad$ g/10MJ per day & $8(3-15)$ & $8(4-16)$ & (max. 10$) \ddagger$ \\
Sugar, added (\%energy) & $14(12-17)$ & $15(12-18)$ & $10-15$ \\
Protein (\%energy) & $4 \cdot 6(0 \cdot 0-13 \cdot 6)$ & $2 \cdot 5(0 \cdot 0-9 \cdot 3)$ & (max. 5)§ \\
Alcohol (\%energy) & & & \\
\hline
\end{tabular}

*Nordic Council of Ministers, 1996.

†The recommendation of $25-35 \mathrm{~g} / \mathrm{d}$ is explained as 'comparable to $3 \mathrm{~g} / \mathrm{MJ}$ per day'.

$\ddagger$ For children and subjects with low energy intake.

$\S$ Maximum value for individuals. 
sample was drawn as a nationwide sample from local telephone registers, aiming at a representative sample with respect to geographical distribution, age and sex.

Dietary intake data: Data were collected through a telephone interview with frequency questions on the following ten foods only: fruit, boiled vegetables, raw vegetables/ salad, potatoes, pasta/rice, fish as a main meal, fish with sandwiches, meat as a main meal, milk, yoghurt. Six frequency alternatives were used. Also, information on the previous day's intake of these foods (yes/no) was collected, and supplementary information on the type of milk and the type of fat habitually used. No information was collected on quantities of intake, and data were analysed and reported as frequencies only. All data were collected during three days (Tuesday, Wednesday, Thursday) in late September 1995.

\section{National dietary survey 1985 from the National Food Agency (Haraldsdóttir et al. 1986, 1987)}

Subjects: 2242 persons (1086 men, 1156 women), 15-80 yrs, participated in this first Danish national dietary survey. Participation rate was $76 \%$. The sample was drawn as a representative sample of the adult population through the central population register (representative as to sex, age and geographical distribution).

Dietary intake data: Data were collected through a personal dietary history interview. Food quantities were estimated by food models, photos and household measures. Data were collected during a three month period, FebruaryMay 1985.

\section{High-fat consumers versus others}

Data from the 1985 national dietary survey were used for the analysis of food intake for high-fat consumers, as this type of data is not yet available from the 1995 national survey.

'High-fat consumers' were defined as subjects belonging to the top quartile (the upper $25 \%$ ) of fat intake (\%energy), for men and women separately. 'Others' were defined as the subjects belonging to the other quartiles of fat intake (\%energy). The number of subjects in these two groups were 560 (271 men and 289 women) and 1682 (815 men and 867 women) respectively.

\section{Statistical analysis}

Differences in mean intakes of foods and certain nutrients (alcohol \%energy, sugar \%energy) were tested by a nonparametric test (Wilcoxon). For other nutrients, a t-test was used. A $5 \%$ significance level was applied.

\section{Results \\ Intake of fat and dietary fibre}

Total fat intake in Denmark is relatively high, median $37 \%$ energy, compared to the recommended mean of $30 \%$ energy (Table 3 ). Less than $10 \%$ of the adult population have a fat intake below $30 \%$ energy, whereas at least $50 \%$ should do this, in order to fulfill the recommended mean intake. When alcohol is not included in the calculation, fat intake is somewhat higher, from 38 to $40 \%$ energy (for women and men respectively). Fatty acid composition is unsatisfactory, with too large a proportion from saturated fatty acids (16\%energy) compared to the poly- and monounsaturated fatty acids (5 and $11 \%$ energy, respectively). The main sources of total fat intake are separated fats (including margarine, butter, oil, etc.: 40\%), meat (18\%), and dairy products $(21 \%$, including cheese). These are also the main sources of saturated fatty acids.

Dietary fibre intake is lower than recommended, $18 \mathrm{~g} / \mathrm{d}$ for women and $22 \mathrm{~g} / \mathrm{d}$ for men. Only $30 \%$ of the men and $15 \%$ of the women reach the lower end of the recommended interval of $25-35 \mathrm{~g} / \mathrm{d}$. Almost two-thirds of the dietary fibre come from cereals $(62 \%)$ compared to vegetables and fruit ( $24 \%$ and $12 \%$, respectively).

\section{Food intake}

Food intake data from the national dietary survey in 1995 are presented in Table 4 . Total mean intake of vegetables and potatoes was only about $200 \mathrm{~g} / \mathrm{d}$ for women and $250 \mathrm{~g} / \mathrm{d}$ for men. Approximately one-quarter of the men, and less than one-tenth of the women, had a total intake of $350 \mathrm{~g} / \mathrm{d}$ or more. The published data from the 1995 survey do not include separate distribution data for vegetables and potatoes. Additional information indicates that on average approximately half of the total was potatoes.

Mean intake of 'fruit and fruit products' (including fresh fruit, juice, jam and other fruit products) was about $150 \mathrm{~g} / \mathrm{d}$ for men and $180 \mathrm{~g} / \mathrm{d}$ for women. Approximately half of the men and two-thirds of the women had a total intake of $100 \mathrm{~g} / \mathrm{d}$ or more. The published data do not include a separate distribution for fresh fruit, but additional information indicates that on average approximately two-thirds of the total was fresh fruit.

Further analysis of the data shows that average intake of 'fruit and vegetables' (potatoes not included) was $277 \mathrm{~g} / \mathrm{d}$, compared to the new recommendation of $600 \mathrm{~g} / \mathrm{d}$ (Trolle et al. 1998). Only $4 \%$ consumed $600 \mathrm{~g} / \mathrm{d}$ or more.

Mean intake of bread and other cereal products (including rice, pasta, breakfast cereals, cakes and pastry) was $190 \mathrm{~g} / \mathrm{d}$ for women and $240 \mathrm{~g} / \mathrm{d}$ for men. On average, bread made up about $60 \%$ of the total mean $(130 \mathrm{~g} / \mathrm{d})$, with nearly half of this as the coarse rye bread, whereas cakes/pastry made up about $20 \%$ of the total mean $(40 \mathrm{~g} / \mathrm{d})$. The published data from the 1995 survey do not include separate distribution data for bread.

\section{Proportion of daily consumers and non-consumers}

A different type of information on food intake was obtained by the simple food frequency survey carried out by the Nutrition Council in 1995 (Haraldsdóttir et al. 1996). The data highlight the proportion of non-consumers versus daily consumers for the different foods (Table 5). Approximately half $(57 \%)$ of the Danish adults reported consuming some kind of vegetables daily or almost daily, and two-thirds $(65 \%)$ did so for fruit. When only every-day consumers were included, these proportions were much lower and only $15 \%$ reported consuming both fruit and vegetables every day. 
Table 4. Food intake (g/d) in Danish adults, 15-80 years, according to a national dietary survey in 1995 (Andersen et al. 1996). Mean and median intakes (10th and 90th centiles) are presented

\begin{tabular}{|c|c|c|c|c|c|c|}
\hline & \multicolumn{3}{|c|}{$\begin{array}{c}\text { Men } \\
(n=904)\end{array}$} & \multicolumn{3}{|c|}{$\begin{array}{l}\text { Women } \\
(n=933)\end{array}$} \\
\hline & Mean & Median & (P10-P90) & Mean & Median & (P10-P90) \\
\hline $\begin{array}{l}\text { Vegetables* } \\
\text { including potatoes }\end{array}$ & 255 & 251 & $(120-417)$ & 205 & 206 & $(105-337)$ \\
\hline $\begin{array}{l}\text { Fruit† } \\
\text { including juice and } \\
\text { other fruit products }\end{array}$ & 152 & 110 & $(18-321)$ & 179 & 149 & $(51-329)$ \\
\hline $\begin{array}{l}\text { Bread } \\
\quad \text { and other cereal products }\end{array}$ & 239 & 234 & $(149-371)$ & 186 & 184 & $(114-273)$ \\
\hline $\begin{array}{l}\text { Meatł } \\
\text { and meat products }\end{array}$ & 142 & 142 & $(76-228)$ & 88 & 91 & $(42-151)$ \\
\hline $\begin{array}{l}\text { Fish } \neq \\
\text { and fish products }\end{array}$ & 24 & 16 & $(0-55)$ & 23 & 15 & $(0-46)$ \\
\hline $\begin{array}{l}\text { Milk } \\
\text { including yoghurt and cream }\end{array}$ & 368 & 317 & $(58-768)$ & 333 & 282 & $(63-643)$ \\
\hline Cheese & 33 & 32 & $(10-66)$ & 31 & 30 & $(10-58)$ \\
\hline $\begin{array}{l}\text { Fats, separated, } \\
\text { including margarine, } \\
\text { butter, oil, etc. }\end{array}$ & 55 & 54 & $(26-92)$ & 40 & 37 & $(18-65)$ \\
\hline
\end{tabular}

* Potatoes comprise approximately half of the total amount.

†Fresh fruit comprise approximately two-thirds of the total amount.

$\ddagger$ Cooked weight.

Almost $10 \%$ of Danish men reported never eating fresh fruit, but this proportion was lower for women. For vegetables overall the proportion of non-consumers was $2 \%$, but as many as $13 \%$ reported never eating raw vegetables or salad, and $7 \%$ never ate cooked vegetables (Table 5). It is worth noticing that these answers mainly refer to vegetables served as such, and that 'non-consumers' may get some vegetables as part of mixed dishes like meat stew.

\section{Food intake among high-fat consumers}

Published data from the most recent national dietary survey, in 1995, do not include separate information on food intake among high-fat consumers. Therefore, results from the previous survey, in 1985, were used for this purpose. High-fat consumers were defined as the top quartile of fat intake (\%energy), for men and women separately. This group was compared to the other quartiles combined together. The difference in average fat intake between the two groups was $10 \%$ energy points, and was counterbalanced by a lower \%energy carbohydrate intake (Table 6). Within the high-fat group, fat intake ranged between 47 and $59 \%$ energy, as compared to 27-47\%energy for the other group. Energy intake was slightly higher in the high-fat group and food intake was therefore compared in relative terms $(\mathrm{g} / 10 \mathrm{MJ})$ instead of absolute intake. High-fat consumers had a lower

Table 5. The proportion (\%) of Danish adults, 15-80 years, who were classified as 'daily' consumers or 'non-consumers' of certain foods, based on a food frequency survey in 1995 (Haraldsdóttir et al. 1996)

\begin{tabular}{lccc}
\hline & \multicolumn{2}{c}{ Daily consumers } & \\
\cline { 2 - 3 } & $\begin{array}{c}\text { Every day } \\
\%\end{array}$ & $\begin{array}{c}\text { Almost every day } \\
\%\end{array}$ & $\begin{array}{c}\text { Non-consumers } \\
\%\end{array}$ \\
\hline $\begin{array}{l}\text { Vegetables* } \\
\quad \text { cooked }\end{array}$ & 11 & 27 & 7 \\
raw/salad & 15 & 21 & 13 \\
$\quad$ cooked or raw/salad & 23 & 34 & -2 \\
$\quad$ neither cooked nor raw & - & - & 6 \\
$\begin{array}{l}\text { Fruit, fresh } \\
\text { Fruit and vegetables }\end{array} \quad$ both fruit and vegetables & 15 & 15 & - \\
Fish & & 28 & 21 \\
$\quad$ as a main meal & & 1 & 23 \\
$\quad \begin{array}{l}\text { as part of a sandwich meal } \\
\text { neither as a main meal nor }\end{array}$ & 7 & 7 & 10 \\
$\quad$ as a sandwich meal & - & - & \\
\hline
\end{tabular}

* Potatoes not included. 
Table 6. Comparison of mean nutrient intake between Danish adults who were classified as high-fat consumers and other subjects. Data from a national survey in 1985, including 2242 subjects, 15-80 years old (Haraldsdóttir et al. 1987)

\begin{tabular}{lcc}
\hline & $\begin{array}{c}\text { High-fat consumers† } \\
(n=560)\end{array}$ & $\begin{array}{c}\text { Others } \\
(n=1682)\end{array}$ \\
\hline Energy, MJ/d & $12 \cdot 3^{*}$ & $11 \cdot 1$ \\
Fat (\%energy) & $50^{*}$ & 40 \\
Carbohydrate (\%energy) & $34^{*}$ & 43 \\
$\quad$ Dietary fibre (g/10MJ per day) & $19^{*}$ & 23 \\
Sugar, added (\%energy) & $6^{*}$ & 9 \\
Protein (\%energy) & $13^{*}$ & 14 \\
Alcohol (\%energy) & $3^{*}$ & 4 \\
\hline
\end{tabular}

* Significant difference between 'high-fat consumers' and 'others', $P<0.05$.

†'High-fat consumers' = subjects in the top quartile of total fat intake (\%energy). Ranking of subjects was done for men and women separately.

$\ddagger$ 'Others' = subjects in the other three quartiles of total fat intake (\%energy).

relative intake of fruit, vegetables, potatoes, bread and lowfat milk, but a higher relative intake of fats (butter in particular), meat and whole milk (Table 7). The higher intake of fats (used on bread as well as in cooking) meant that the high-fat consumers got as much as $56 \%$ of their total fat intake from this food group, compared to $48 \%$ for the others. The difference in fat intake was observed for all meals (Table 8).

\section{Discussion}

The Danish food-based dietary guidelines have generally been expressed in simple terms, aiming at communicating the essentials of a healthy diet to the general public. This

Table 7. Comparison of relative food intake $(\mathrm{g} / 10 \mathrm{MJ})$ between Danish adults who were classified as high-fat consumers and other subjects. Data from a national survey in 1985, including 2242 subjects, $15-80$ years old (Haraldsdóttir et al. 1987)

\begin{tabular}{lcc}
\hline & $\begin{array}{c}\text { Ratio of intake, } \\
\text { 'high-fat consumers' } \dagger \\
\text { /'others' } \ddagger\end{array}$ & $\begin{array}{c}\text { Difference in } \\
\text { intake } \\
\text { g/10MJ }\end{array}$ \\
\hline Fruit, fresh & 0.54 & $-41^{*}$ \\
Vegetables & 0.83 & $-23^{*}$ \\
Potatoes & 0.89 & $-14^{*}$ \\
Bread & 0.87 & $-27^{*}$ \\
Milk, totall & 0.72 & $-113^{*}$ \\
wholemilk (3.5\% fat) & 1.26 & $+28^{*}$ \\
low-fat milk (1.5\% fat) & 0.59 & $-60^{*}$ \\
skimmed milk (0.1\% fat) & 0.34 & $-57^{*}$ \\
Fats, total & 1.42 & $+23^{*}$ \\
butter & 1.82 & $+14^{*}$ \\
margarine & 1.12 & $+4^{*}$ \\
Meat & 1.12 & $+12^{*}$ \\
Fish & 1.00 & $0 \mathrm{~ns}$ \\
Beverages & & $-42 \mathrm{~ns}$ \\
beer & 0.72 & $-12^{*}$ \\
wine & 0.76 & $+28 \mathrm{~ns}$ \\
soft drinks & 1.41 & \\
\hline
\end{tabular}

* Significant difference between 'high-fat consumers' and 'others', $P<0.05$.

†'High-fat consumers' = subjects in the top quartile of total fat intake (\%energy). Ranking of subjects was done for men and women separately.

* 'Others' = subjects in the other three quartiles of total fat intake (\%energy). $\S$ Difference $=$ (intake of 'high-fat consumers') - (intake of 'others').

$\|$ Yoghurt not included.
Table 8. The fat content (\%energy) of different meals for Danish subjects classified as high-fat consumers compared with other subjects. Data from a national survey in 1985, including 2242 subjects, 15-80 years old (Haraldsdóttir et al. 1987)

\begin{tabular}{lcc}
\hline & $\begin{array}{c}\text { High-fat consumers } \\
(n=560) \\
\% \text { energy }\end{array}$ & $\begin{array}{c}\text { Othersł } \\
(n=1682) \\
\% \text { \%energy }\end{array}$ \\
\hline Breakfast & $48^{*}$ & 37 \\
Lunch & $52^{*}$ & 43 \\
Supper & $50^{*}$ & 43 \\
Snack meals & $41^{*}$ & 34 \\
\hline
\end{tabular}

*Significant difference between 'high-fat consumers' and 'others', $P<0.05$.

†'High-fat consumers' = subjects in the top quartile of total fat intake (\%energy). Ranking of subjects was done for men and women separately.

$\ddagger$ 'Others' $=$ subjects in the other three quartiles of total fat intake (\%energy).

form is too vague to stand alone and give sufficient guidance to consumers; the guidelines are also too vague to be a useful tool for food policy and public health nutrition purposes. The guidelines therefore need to be elaborated by including recommendations on quantities. This has now been done for fruit and vegetables, recommending $600 \mathrm{~g} / \mathrm{d}$ (Trolle et al. 1998).

The intake data presented above mainly focus on fat, dietary fibre, and fruit and vegetables. Fat intake in Denmark is higher than recommended, in particular intake of saturated fatty acids. A main source of fat is separated fats (butter, margarine, oil, etc.) in particular among high-fat consumers. This may partly be explained by the fact that in Denmark one of the main meals, lunch, is usually a sandwich meal where bread and spreads are main ingredients. As a result of the first national dietary survey in 1985, information campaigns with a specific focus on the reduction of fat intake were started. The next survey, ten years later, showed a lower fat intake. Apparently this decrease was from a median value of $43 \%$ energy in 1985 to $37 \%$ energy in 1995 , but a part of it was due to differences in the dietary intake methodology (which could account for at least one-third of the decrease). Differences between the population samples may also have played a role as participation rate was much lower in the 1995 survey (58\% versus $76 \%$ in the 1985 survey, for the age group 15-80 years). So although total fat intake certainly decreased during these ten years, the true magnitude of the reduction was smaller than indicated by the crude values. In contrast to this positive trend in total fat intake, there was no improvement in fatty acid composition from 1985 to 1995.

Intake of fruit and vegetables is relatively low in Denmark, in particular if potatoes are not included. The new recommendation of $600 \mathrm{~g} / \mathrm{d}$ is twice the average intake, and only $4 \%$ meet that recommendation. Compared to the general guideline 'Eat fruit and plenty of vegetables every day', only a small part of the population $(15 \%)$ report consuming both fresh fruit and vegetables every day. Although a larger number $(28 \%)$ report doing this almost every day, it does not indicate a satisfactory intake, as it is difficult to consume as much as $500-600 \mathrm{~g} / \mathrm{d}$ without an every-day intake. Increasing the content of fruit and vegetables in the average Danish diet to the recommended $600 \mathrm{~g} / \mathrm{d}$ will increase dietary fibre intake, typically by $50 \%$ (from $20 \mathrm{~g} / 10 \mathrm{MJ}$ to 
$30 \mathrm{~g} / 10 \mathrm{MJ})$ provided that cereal intake is not reduced (Trolle et al. 1998).

The new recommendation for intake of fruit and vegetables is communicated to the general public in a simple slogan ' 6 a day - eat more fruit and vegetables' and further explained in terms of pieces of fruit and grams per day. For a country like Denmark where the potato is a traditional staple food it makes a substantial difference whether or not it is included in the recommended amount of 'fruit and vegetables'. In the new Danish recommendation, potatoes are not included in the $600 \mathrm{~g} / \mathrm{d}$ but the background document explicitly encourages consumption of potatoes as a highcarbohydrate staple food (Trolle et al. 1998).

Food-based dietary guidelines are primarily established for planning and education purposes, but they may also be useful in other contexts. At present most dietary surveys evaluate intake in terms of nutrients only, paying little attention to foods except as sources of nutrients, and one explanation for this is the lack of reference values for food intake. Quantitative food guidelines may have an important contribution in this context by providing reference values for evaluation of intake.

\section{References}

Andersen NL, Fagt S, Groth MV, Hartkopp HB, Moller A, Ovesen L \& Warming DL (1996) Danish dietary habits 1995 (In Danish with an English summary). Publ. no. 235. Copenhagen: Danish Veterinary and Food Administration.

Haraldsdóttir J, Holm L, Jensen JH \& Moller A (1986) Danish dietary habits 1985. 1. Main results (In Danish with an English summary). Publ. no. 136. Copenhagen: National Food Agency.*

Haraldsdóttir J, Holm L, Jensen JH \& Moller A (1987) Danish dietary habits 1985. 2. Who eats what? (In Danish with an English summary). Publ. no. 154. Copenhagen: National Food Agency.*

Haraldsdóttir J, Holm L \& Jensen H (1996) Surveillance of food consumption using telephone interviews (In Danish with an English summary). Ugeskrift for Laeger 156, 7402-7406.

Forbrugerstyrelsen (National Consumer Agency) (1995) De syv kostraad (In Danish). Copenhagen: Forbrugerstyrelsen.

Nordiska Ministerraadet (Nordic Council of Ministers) (1996) Nordiska näringsrekommendationer 1996 (In Swedish). Nord 1996 28. Copenhagen: Nordisk Ministerraad.

Trolle E, Fagt S \& Ovesen L (editors) (1998) Fruit and vegetables, recommendations for intake (In Danish). Publ. no. 244. Copenhagen: Danish Veterinary and Food Administration. 